\title{
Application of Learner-Centered Approach in College English Instruction in China: A Case Study
}

\author{
Shengnan $\mathrm{Du}^{1}$ \\ ${ }^{1}$ EIT Data Science and Communication College, Zhejiang Yuexiu University, Shaoxing, China \\ Correspondence: Shengnan Du, EIT Data Science and Communication College, Zhejiang Yuexiu University, \\ Shaoxing, Zhejiang, China.
}

Received: August 13, 2021

Accepted: September 9, 2021

Online Published: September 13, 2021

doi: 10.5539/elt.v14n10p23

URL: https://doi.org/10.5539/elt.v14n10p23

\begin{abstract}
With a development history of more than half a century, the learner-centered approach has become a new teaching paradigm worldwide. The approach can produce effective and significant learning focusing on learners' development, learning, and learning outcomes. This study aimed to determine how a learner-centered approach can increase students' engagement, improve their English learning strategies, and enhance their academic performance in a specific EFL setting. Bloom's taxonomy, Zhao's "Neo Tri-Centers," Krashen's L2 acquisition theory, and primarily Biggs' constructive alignment functioned as valuable guidelines when designing the instructional activities. Constructive alignment holds that intended learning outcomes, teaching and learning activities, and assessment tasks should be aligned organically to achieve effective learning. Data collected through the instructor's observations, questionnaires, assessments of the students' performances, and colleague's feedback show that the learner-centered approach has remarkably motivated the students, improved their learning strategies, and enhanced their academic performance. The results and implications of this study may be of reference importance for future language teaching in a foreign language or second language setting.
\end{abstract}

Keywords: learner-centered approach, college English instruction, EFL setting, effective teaching and learning

\section{Introduction}

Since Carl Rogers propounded his view of student-center (SC) teaching in the 1950s based on his psycho-therapeutic principles, the world has witnessed significant educational field changes. Currently, student-centered interchanges learner-centered (LC) on many occasions. However, this study holds that the latter is a more appropriate descriptor. Student-centered implies a schooling context. Consequently, the misconception that once students end their formal education, the positive effect of instruction on them will soon stop functioning is likely to occur.

Nevertheless, the instructional activities of all educational organizations and institutions should focus on helping students grow into lifelong learners. John Dewey once put in his Democracy and Education, "the aim of education is to enable individuals to continue their education" (2004: 108). That is to say, instructional activities at various levels should see the stable identity of students as lifelong learners, which is not bound to school or college gates. This perception is even more accurate with higher education because colleges or universities are their last stop of formal education for many students. Thus, the primary aim of a college education should be helping students develop into lifelong learners with independent learning abilities. In this sense, it is more appropriate to use learner-centered descriptor when it refers to tertiary education.

In China, college English usually given to non-English majors is an indispensable part of higher education curricula. Mainly consisting of English for General Purposes, English for Specific Purposes, and Cross-Cultural Communication courses (Xiang, 2020: 31), college English aims to strengthen students' English communicative competency and promote their personal and humanistic quality (ibid: 30 ). With English as a lingua franca in this ever-deepening globalized world, the importance of college English instruction in China cannot be overstated. In 2020, the revised version of College English Teaching Guidelines released by the National College Foreign Language Teaching Advisory Board "redefined college English as General Education" (Cai, 2021: 4), which perfectly illustrates the growing importance of college English instruction. To optimize college English instruction, teachers in the English discipline in China have been trying different teaching techniques, methods, 
and strategies in their instructional practice. This study aims to improve student's learning outcomes with the employment of the LC approach and is guided by the following three questions:

a) What kinds of LC activities can be designed to increase students' engagement in college English instruction in a specific EFL setting?

b) What kinds of LC activities can help students foster effective English learning strategies in a specific EFL setting?

c) To What extent can the employment of the LC approach in college English instruction improve students' academic performance in a specific EFL setting?

\section{Literature Review}

\subsection{The Beginning and Development of LC Approach}

The LC approach to teaching embarked on its journey when C. R. Rogers, an exceptional American psychologist famous for his "client-centered therapy" (1946: 415-22), was invited by Harvard University to demonstrate his view of SC teaching in a conference on "Classroom Approaches to Influencing Human Behavior" (Rogers, 1961: 273). His five do-aways, namely do away with teaching, examinations, grades and credits, degrees, and the exposition with a conclusion (ibid: 277), agitated members of the conference. Although Rogers' demonstration was met with "indignation, frustration and criticisms" (ibid: 274), yet his idea that significant learning is self-directed and "cannot be directly communicated to another" (ibid: 276) found its justification in the theory of the influential cognitive psychologist, J. Piaget. According to Piaget, each individual has a cognitive structure of their own based upon which they construct knowledge (1971). In this light, effective learning can not be achieved through traditional teacher-centered teaching. Piaget's theory suggests that teachers should consider students' schemata and connect new knowledge to their current stages of cognitive development. Bloom's Taxonomy of Educational Objectives (1956) first classified different levels of learning according to cognitive development levels. The taxonomy, revised in 2001, has been guiding teachers' instructional practice ever since its invention. Both the SC teaching concept of Rogers and cognitive constructivism, born out of Piaget's theory and brain science, emphasize the importance of the learner's inner force.

Social constructivism growing out of the works of L. S. Vygotsky and others, on the other hand, gives equal importance to external and internal forces. Vygotsky believed that sociocultural context inevitably shapes human beings' minds and that meaningful learning happens when learners' actual development level is activated through interactions with the environment and collaborations with peers (Daniels, Cole, \& Wertsch, 2007). The importance of learning context or environment was reemphasized when J. Lave and E. Wenger propounded situated learning based on their researches on the apprenticeship of midwives, tailors, quartermasters, butchers, meat cutters, and non-drinking alcoholics (1991). The SC concept of Rogers and the belief of cognitive constructivism shifted the focus of teaching from teachers to students. Moreover, the tenet of social constructivism extended the context of teaching from classroom to social reality and community, which changed colleges and universities from ivory towers into bridges linking students with real life.

\subsection{The Flourishing $f$ LC Approach}

With the joint efforts of brain scientists, cognitive psychologists, and educational psychologists, SC teaching developed into a national-wide schooling reform in the 1990s in the United States, and its influence spread gradually to other countries. In 1997, to propel effective schooling reform, American Psychological Association released Learner-Centered Psychological Principles. Additionally, at the beginning of the 21st century, a monumental book, How People Learn: Brain, Mind, Experience, and School (Bransford, 2000), was published. Under the valuable and reliable guidance of the two publications, the new teaching paradigm began to flourish. Probably also under the influence of them, the descriptor LC came into existence. Based on their researches and reform experiences, many scholars and practitioners in the US published papers, books, or monographs to share instructional model designs, techniques, and strategies of SC/LC education. According to Gao, those instructional design models can be classified into three types: the general model, the method-specific model, and the discipline-specific pedagogy $(2019,233-37)$. By reading literature on American SC reform, Gao collected more than three hundred SC instructional methods (ibid: 98). She classified them into six major types in terms of different functions, namely reality-based learning, active learning, collaborative learning, general educational learning, professional learning, and active lecturing learning (ibid: 99-104).

Among the numerous books on SC/LC instruction, four of them may well be of particular guidance value to beginners who want to practice the new teaching paradigm. The first book is Learner-centered teaching: Five key changes to practice (2002). In this book, Weimer presented the characteristics of LC teaching and illustrated 
her view on how to implement the LC approach with her course Speech Communications $100 \mathrm{~A}$ as an example. The second one is Helping students learn in a learner-centered environment: a guide to facilitating learning in higher Education (Doyle, 2008). The book gives brilliant points on how to "prepare students for the new roles and responsibilities they would be asked to take on in this new learning paradigm" (ibid: xvii), which will make efforts in practicing LC teaching more fruitful. The third one is Teaching for Quality Learning at University: What the Student Does (Biggs \& Tang, 2011). The book holds that effective teaching and learning happens when "the connections between ILOs, TLAs, and ATs are aligned intrinsically" (ibid: 99). ILOs, TLAs, and ATs stand for intended learning outcomes, teaching and learning activities, and assessment tasks, respectively. With sound empirical evidence, the book proves constructive alignment an effective learning-centered method to improve tertiary education. The last book is McKeachie's teaching tips (McKeachie \& Svinicki, 2014). It provides a wide variety of practical strategies and skills that teachers can adopt to attain quality instruction.

\subsection{LC Approach in China}

In the mainland of China, SC rather than LC is more commonly used. The introduction of the SC teaching concept into China can be traced back to the early 1980s. From the 1980s to 2010s, periodicals based on teaching experiments were the predominant form of SC research, and their number increased gradually. However, those periodicals did not successfully arouse attention within the academic field. Between 2011 and 2019, CNKI (China National Knowledge Infrastructure) witnessed a remarkable increase in publications on SC teaching. Many seminal American works on SC/LC learning and teaching were also translated into Chinese during this period. Nevertheless, the new teaching paradigm did not obtain its wide attention in China until 2018, when the Department of Higher Education became determined to improve the quality of undergraduate education.

One prominent scholar must be mentioned during the critical period. Zhao Jing, a Professor from Huazhong University of Science and Technology, began his study of "student-centeredness (SC) undergraduate educational reform in the USA" (2016: 56) in 2010. The study lasted for ten years, during which he published a series of influential papers. The first of those papers presents the concept of SC and a brief history of American SC undergraduate educational reform (ibid.); the second "addresses the scientific foundations of the reform" (2017a: 52); the third probes "effective instructional practices and methods" (2018a: 44); the fourth discusses "learning environment and educational technology" (2019: 25); the fifth "introduces the framework and logic of educational quality assurance system in American colleges and universities" (Zhao \& Gao, 2019: 20); the sixth "introduces the major methods of course-level learning outcome assessment innovated by the American universities and colleges in its SC reform" (Zhao, 2019: 23); the seventh focuses on Scholarship of Teaching and Learning (Zhao \& Gao, 2020); the eighth analyzes "the issue of the 'overemphasized research and devalued teaching' in faculty performance evaluation" (Zhao, 2020: 27); the last "mainly focuses on leadership, organization and management for a successful SC reform" (Zhao, 2021: 22). Based on his researches, Zhao put forward "Neo Tri-Centers" representing "student development, student learning, and learning outcomes," the "three central concerns" (2016: 56) of SC reform in education. He also propounded 3650 Frame (2018b: 37) to guide teachers in China to design their courses in the SC way. The number 3 represents the Neo Tri-Centers; 6 the six levels in the cognitive domain of Bloom's taxonomy; 5 the five elements in active learning, namely the usefulness of knowledge, the authenticity of learning, challenging tasks, social context, and interactive process; finally 0 the ten elements of effective learning, namely construction, self-discipline, activities, experience, context, internalization, cooperation, accumulation, repetition and diversity (ibid.). Zhao's unprecedented systematic study functions as a valuable map of SC undergraduate educational reform in the USA and provides significant implications for SC reform in China.

\section{Methodology}

\subsection{Before Implementation}

Comprehensive English 2, a compulsory course given to first-year students at X University, was chosen to conduct this study. The research group is class 2, cohort 2020, majoring in Management and Application of Big Data at X. The group includes 13 females and 23 males. Quantitative and qualitative analyses of the class' performance in Comprehensive English 1 last semester had been done before LC approached was implemented in the new semester. Of all the 36 students in the class, six students failed (a score less than 60 out of 100 points equals fail) Comprehensive English 1, with the lowest being 41. The average score of the course is 68.6. Qualitative data were collected through formal and informal talks between the students and the instructor and in-class observations in the last semester. Two significant results, extracted via analyzing these qualitative data, follow: (a) most of the students had high learning anxiety and low learning self-confidence and were thus less engaged in learning; (b) most of them have poor English learning strategies. 


\subsection{During Implementation}

The teaching experiment is situated in a conceptual framework that views the LC approach as achieved through the organic combination of "Neo Tri-Centers" (Zhao, 2016), constructive alignment (Biggs \& Tang, 2011), Bloom's taxonomy (Anderson et al., 2001) and L2 acquisition theory (Krashen, 1998). The three key centers, "student development, student learning, and learning-outcomes" (Zhao, 2016: 56), function as the guiding principles in designing teaching and learning activities. To ensure quality learning outcomes, the instructor used the constructive alignment concept at the course level (Biggs \& Tang, 2011) to design the teaching plan. Cognitive verbs from the revised Bloom's taxonomy (Anderson et al., 2001) were employed to make teaching instruction specific and measurable. Given that English is a foreign language to all the participants in the research, L2 acquisition theory was also considered when the instructor was designing teaching and learning activities. The monitor hypothesis (Krashen, 1998: 30-32), the input hypothesis (ibid: 32-37), and the affective hypothesis (ibid: $38-39$ ) all served as valuable guidelines in the experiment.

\subsection{After Implementation}

After implementing the LC approach, data were collected through the instructor's observations, assessments of students' performances, closed and open-ended questionnaires, and feedback from colleagues. Closed questionnaires required participants to select their answers from the given choices, namely Yes, No, and Not Sure, while open-ended questionnaires gave open-ended questions. Questionnaires were conducted through the website www.wjx.cn and given to the students at the end of each unit and the semester. Closed questionnaires aimed to investigate their attitudes and perceptions towards the LC activities used by the instructor. Open questionnaires delved into these attitudes and perceptions, in addition to producing information about their self-reflection on learning. Quantitative analyses were given to the data collected through assessments and closed questionnaires. Qualitative analyses were given to the data collected through observations, open-ended questionnaires, and colleague feedback through categorizing and identifying emerging themes. The results elicited from the two kinds of analysis are used to illustrate how well the three guiding questions listed in the introduction are answered and explore what implications they contain. Out of privacy protection, all of the names of the students mentioned in this paper are pseudonyms.

\section{Implementation of LC Approach in Comprehensive English 2}

\subsection{A General Structure of the Implementation}

\subsubsection{Course Aim}

Comprehensive English 2 aims to help the first-year students at $\mathrm{X}$ university develop their linguistic and communicative competencies through listening, speaking, reading, and writing activities based on four topics, namely "College culture," "Mixed feelings," "Sporting life," and "Crime watch" (Greenall \& Wen, 2019: 1, 19, $39,57)$ which are highly relevant to their daily life and might arouse their interest in learning. Linguistic competence means identifying English lexical, syntactic, semantic, and discourse knowledge and adequately using the knowledge to auto-correct one's English outputs. Communicative competence means using acquired English to express and exchange ideas, opinions, needs, and desires in informal and formal situations. By adopting collaborative, dialogic, and task-based learning activities, the course also aims to cultivate most of X's graduate attributes, particularly critical thinking, teamwork spirit, self-regulation, and creativity.

\subsubsection{ILOs, TLAs, and ATs of the Course}

The intended learning outcomes for the students:

a) recognize the words, expressions, and knowledge covered in the course when you hear them or see them;

b) paraphrase complex expressions and sentences in classroom discussion;

c) analyze the structures of the assigned reading texts and generalize main ideas of them through individual and collaborative work;

d) evaluate the writing skills, purposes, or motifs of the texts after reading them through;

e) compose writings with vocabularies or writing skills you have obtained from the course, or give presentations or performances on the subjects you have learned in the course based on what you have experienced or observed in reality. 
The aligned teaching and learning activities follow ("I" represents the instructor; "Ss" represents the students):

a) I: provides background information of the assigned reading texts; gives dictations when Ss have finished learning the content and structure of each assigned reading text.

Ss: memorize and understand the vocabularies that are new to them in each assigned reading text individually with the help of tool books; finish dictations given by the instructor.

b) I: arranges Think-Group-Post-Share classroom activities to guide Ss to interpret the complex expressions, sentences, and main ideas in the assigned reading text through collaborative work; elaborates expressions, sentences, and main ideas in the assigned reading text that Ss still have difficulties in understanding after individual and collaborative work.

Ss: figure out the meanings of the complex expressions and sentences posed by each group member and discuss the main ideas of the assigned reading texts through the Think-Group-Post-Share activities under the instructor's guidance.

c) I: introduces to Ss the basic structures and elements of different genres illustrated by the assigned reading texts and recommends some frequently used mind maps.

Ss: individually analyze the organizations of the assigned reading texts using mind maps before class and share them in class.

d) I: guides Ss to form their own opinions on writing skills, purposes, or motifs through questions and discussions.

Ss: evaluate the assigned reading texts' writing skills, purposes, or motifs by answering questions and participating in discussions.

e) I: facilitates Ss' writings, presentations, or performances with feedback and scaffolding.

Ss: create writings, presentations, or performances with the knowledge and skills they learned.

The aligned assessment tasks are coursework (50\%) and final exam (50\%). The final exam is a traditional assessment form of the course and to change the tradition involves joint efforts from different levels. Therefore, a final exam is still taken as an effective form of assessment in this study. The coursework mainly includes dictations, quizzes, writings, individual presentations, group presentations, and role play. The final exam consists of multiple choices, matching, blank filling, reading comprehension, translation, and writing.

\subsection{A Specific Example of the Implementation}

\subsubsection{Topic and Passage}

To illustrate how the LC approach was implemented in Comprehensive English 2, the instructional activities of the last topic, "Crime watch" (Greenall \& Wen, 2019: 57), will be presented in this part. The text chosen to display this topic is "After twenty years" (ibid: 59-61), a short story by the American writer O' Henry, which tells the fulfillment of an appointment made twenty years ago by two late teens. The reasons for the choice are: Chinese students are familiar with O' Henry and his writing style, which will lower learning anxiety to some extent; suspense in the fictional narrative can hold students' interest in reading; despite the use of some slang and several complicated sentences, the story is primarily made up of dialogues and is thus comparatively easy for the students to comprehend; the richness of the themes conveyed through the story provides enough space for students to connect, discuss, share and reflect.

\subsubsection{Instructional Activities of "After twenty years"}

\section{(1) Present ILOs and ATs to the students}

Katherine, one of the six students who failed Comprehensive English 1, once told the instructor that she was extremely nervous when sitting in English classes last semester and is still so when having English classes given by a native speaker. "The moment I am seated in the oral English class, I begin to get anxious about when my name will be called and whether I will be able to answer the teacher's question or not," she said. Additionally, according to the instructor's observation, many students have no idea what knowledge and skills they should learn or acquire from instructional activities until they are asked to finish their assignments. Given the above, it is conducive to students' learning if the ILOs and ATs of each new text are introduced to them before the actual instructional activities unfold. Hence, the following ILOs and ATs of "After twenty years" are presented to the students at the beginning of this new session. Notice that some ILOs overlap with ATs. 
a) Recall some basic information about O' Henry and his writing style; recognize the new words and expressions in "After twenty years" when you hear them or see them; a dictation will be given when we finish an intensive reading of the story.

b) Analyze the structure of "After twenty years" and generalize the main ideas using mind maps.

c) Paraphrase the complicated expressions and sentences in "After twenty years" and contribute to the Think-Group-Post-Share activity; finish exercises 4-8 on pp. 62-64 by yourselves after class.

d) Share your interpretation of the story's motif with evidence drawn from the text.

e) Imagine a scenario of your life ten years from now, create and perform a drama titled "After ten years" with your group members.

\section{(2) Actualize the Aligned TLAs}

The aligned TLAs begin with the ones aiming to help students grasp some basic information about the author and his writing style. Since the students are familiar with O' Henry, warming up activity was used to activate students' prior knowledge. The question "Do you know who William Sydney Porter is" was met with a unanimous no, as had been expected by the instructor. With a perceived increase in curiosity, another question, "Then do you know who O' Henry is" was asked and met with a unanimous yes. The students realized for the first time that $\mathrm{O}^{\prime}$ Henry is a pen name. Next, the representative works of $\mathrm{O}^{\prime}$ Henry and his writing style were elicited from the students via more questions. The Q\&A section was then closely followed by a listening activity. The listening material giving a general introduction to O' Henry's life and his writing style functioned as a consolidation and supplement to the previous knowledge collected from the students.

After the warming up, students were asked to skim the story to find their answers to the question: why is the story titled "After twenty years"? This reading activity aimed to exercise the students' ability to reach a general idea of a text through skimming. Not allowed to look up unfamiliar words, the students were encouraged to guess the meanings of keywords through contexts. According to the instructor's observation, many students in this class developed a habit of looking up every unfamiliar word while reading a text for the first time, which prohibits them from becoming efficient readers. In-class reading activities as such can help them get rid of the bad habit. To alleviate learning anxiety, the instructor encouraged the students to exchange their opinions within their groups (they were required to sit in groups from the beginning of the semester) before sharing their answers.

"After twenty years" is narrated chronologically, so it was relatively easy for the students to follow its plot. Nevertheless, to attain a deep understanding of the story's structure, they need knowledge of the elements of the plot. The good news was that they, as college students, had already acquired that knowledge in L1 classes at their primary or secondary schools. Therefore, the instructor only had to activate that knowledge in their mind with some short questions and introduce those elements' English equivalents. The instructor strung the five elements, namely exposition, rising actions, climax, falling actions, and ending, with an opening downward parabola to facilitate their long-term memory. With such a parabola in their mind, they were then required to individually analyze the story's structure with mind maps after class. The students could use either the mind map models recommended by the instructor in the Wechat group or the ones they found by themselves. While analyzing the structure, they also needed to read through the story again and look up unfamiliar expressions with the vocabulary handbook or dictionaries. Before dismissing the class, the instructor reminded the students to conceive their group play and performance from now on. A form and grading rubrics had been uploaded to Yunbanke, a popular platform for online instruction in China, to help them finish the assignment. Extra help and guidance from the instructor were always available to them via Yunbanke and Wechat.

When the students came to the class again with their mind maps and increased familiarity with the story, they were required to share, think and discuss. They were given ten minutes to share their mind maps within their groups. During the sharing, the students reflected on and rectified their mind maps by agreeing and disagreeing. While the students were sharing, the instructor was circulating in the classroom and providing help when needed. When time ran out, the instructor invited several of them to share their mind maps with the whole class. The instructor gave more positive comments than negative ones to build their confidence in learning.

After analyzing the structure, the students carried out Think-Group-Post-Share activity to interpret, paraphrase and analyze the complex expressions and sentences in the story that puzzled them. They were given time to think individually and find out the expressions and sentences that still confused them after individual endeavors. They were then asked to exchange their self-detected complicated expressions and sentences within their groups. While exchanging, they were also encouraged to solve as many complex expressions and sentences as possible 
through group wisdom. For the unsolved complex expressions and sentences, the students wrote them down on post-it notes and posted them onto the whiteboard. With the employment of such teaching strategies as pausing, bouncing a question, inviting third party ideas, and turning telling into asking, the instructor cleared up the remaining lexical, syntactic and semantic confusions by inviting each student to share their knowledge. After the activity, the students had to finish exercises 4 to 8 on pages 62 to 64 by themselves after class. They were also required to finish watching a TED talk titled "Why 30 is not the new 20" by Meg Jay via the link shared by the instructor in the Wechat group and think about how the speech connects to "After twenty years" in motifs.

The rest of the in-class instructional activities were: checking answers to exercises 4 to 8 on pages 62 to 64 to see how well the students had learned or acquired the lexical and semantic items in the story; The students' justifying their interpretations of the story's motifs and how the speech by Meg Jay connects to the story; guiding them to connect the story more closely to themselves through an extended reading on "emerging adulthood" (Arnett, 2015); students performing their group dramas "After ten years." Checking answers to exercises could have been done efficiently by the students themselves if only the majority of them were highly self-regulated. Supervised by the instructor, the activity functioned as formative feedback to both teaching and learning. An intertextual reading between the fictional and nonfictional led the students to discover the real significance of "After twenty years." The group performance needed the students to apply their linguistic knowledge, exercise their communicative competency, reflect the social reality and exert their imagination.

\section{(3) Assess the Realization of the ILOs}

To assess how much the students can recall the general background information of O' Henry and his writing style, a game-based assessment tool, bodoudou, was employed. The instructor designed eight multiple choices with the tool, and the students scanned the QR code with their Wechat to enter the game room. On finishing each question, the students saw their place in a real-time ranking list, the correct answer, and the correct rate. This assessment activity made feedback exhilarating, transparent and efficient.

Both formative and summative assessments were adopted to assess how well the students can recognize the new words and expressions in "After twenty years" and assess their ability to paraphrase obscure expressions and complicated sentences. Finishing exercises attached to the story and participating in Think-Group-Post-Share were formative, and taking dictation was summative. The finished exercises were self-checked by the students and not graded. Likewise, performance in Think-Group-Post-Share was observed by the instructor and not grade. On the contrary, the dictation was peer-graded, and its scores were taken into total course scores. Moreover, in the final exam, multiple choices, matching, blank filling, and translation aimed to assess the students' lexical, syntactic, and semantic knowledge.

To assess how well the students analyze the structure and the motif of "After twenty years" and how successfully they can apply a basic fictional narrative structure, formative and summative assessments were again used. Their revised mind maps after group sharing were graded as a part of the in-class performance. Their discussions and explanations of the story's motif were not graded but commented on. The group drama performances requiring them to create a plot and theme with what they had learned or acquired were graded. The form guiding the students to finish the performance required them to fill out such contents as setting, plot, theme, and cast list, which took up $20 \%$ of the total. Each group form was expected to be revised at least one time under the instructor's advice. The performances, representing $80 \%$ of the total, were graded by peers and the instructor (half and half) according to the grading rubrics uploaded to Yunbanke early on. The students were given a choice over the form of their performance. They could either give a live performance in class or bring their recorded performance to class.

\section{Results and Discussion}

All 36 students responded to the questionnaires distributed to them. With the aim to echo the three questions guiding this study, the results and discussion will be presented in three aspects: enhanced engagement, better learning strategies, and improved academic performance.

\subsection{Enhanced Engagement}

\subsubsection{Game-Based Learning Assessment}

Game-based learning assessment proved to be remarkably effective in enhancing the students' engagement. $88.89 \%$ of the respondents reported that game-based assessment made them more engaged in class in the closed questionnaire. Many students also expressed their love for it in the open-ended questionnaire, as Michael wrote: 
"I have long thought game-based learning is good. It is a new way of learning...First, it has limited time. Second, it has strong feedback. You can know right away your answer is wrong or right. Finally, the ranking will produce dopamine in me...All in all, it makes me focus and remember something."

According to the investigation by Zhu Lin, only $11.7 \%$ of the investigated college students do not play online games, and $65.3 \%$ of them spend more than one hour per day playing online games (2021: 147). No doubt, being fascinated by online games is a vital characteristic of today's college students. To many of them, video games entertain them and give them a sense of achievement. In LC teaching, instructors can motivate students' involvement by embedding learning in gaming through some handy apps.

\subsubsection{Think-Group-Post-Share Activity}

$83.33 \%$ of the respondents reported in the closed questionnaire that Think-Group-Post-Share made them participate more actively and become more attentive in class. The effectiveness of the activity was also well noticed by the dean of Y College at $\mathrm{X}$ when he was observing the class. Listed below is his feedback:

"Obviously, it was enjoyable to visit such a class...All the students took an active part in the class. They either listened attentively to the instructor or engaged enthusiastically in class discussions. They sometimes pondered, sometimes raised questions for what they had heard. Everyone was busy and active in the class."

Many teachers consider lexical, syntactic, and semantic items the crucial part of this course's instruction. In teacher-centered instruction, these items are commonly addressed through lecturing. Instructors exemplify the meanings, usages, and sometimes inflections of the words and expressions they think are important or challenging to students. They also explain grammar that they think is useful or difficult to students. Based on first-hand experience and what the instructor has learned via exchanging teaching experience with coworkers, this way of telling or demonstrating is tiring to instructors and boring to students.

The study found that this tiredness and boredom had significantly been relieved through Think-Group-Post-Share activity. The reasons for this can be: students assumed their responsibility for learning, and they made their voices heard. Thinking independently provided an opportunity for students to exercise autonomous learning and the ability to ask questions. Group discussion developed their ability to solve difficulties in learning through collaborative efforts. Posting their remaining difficulties after group discussion informed the instructor of what kind of help they precisely needed. Tackling the remaining difficulties through knowledge and opinions shared by both students and the instructor generated stimulating dialogues.

\subsubsection{Lowered Anxiety and Boosted Confidence}

As mentioned previously, high learning anxiety and low learning confidence found in many students in class 2 inhibited active involvement. Data collected from the open-ended questionnaires show that challenging assignments that students can finish with current knowledge and skills, learning activities relevant to students' personal life and experience, assignments stimulating students' imagination, and timely encouragement from the instructor lowered students' learning anxiety and boosted their learning confidence. Victoria wrote the following:

"I can finish the extended reading materials provided by the teacher although I do not know all the words in them. I can have my idea because I understand the content, and I feel a sense of achievement."

Activities like presenting your views on the value of higher education and sharing an unforgettable sports moment in your life eased the students' learning anxiety to some extent, but it was the strenuous efforts from the students that completely subdued the anxiety, as Scott wrote:

"Last semester, I was quite afraid to give a presentation. But this semester, I can present my opinions quite fluently through practice. In the beginning, my voice was shaking, but now I can at least face it composedly. For me, this is big progress, and it is the source of my sense of achievement."

Therefore, in addition to designing authentic learning activities, instructors should also think of ways to inspire students to spend more time practicing English.

When creative assignments successfully arouse students' interest, "desirable but unintended learning outcomes" (Biggs \& Tang, 2011: 191) can happen. Although in the assignment of drama performance "After ten years" each group was asked to give only one performance, one group gave two performances. Given below is the reflection by a member of the group.

William: "In 'After ten years', because we paid, our performance was praised by the teacher and classmates' applause made me feel successful. The applause let me feel everything I did is worth it. It also made me work harder." 
For students lacking learning confidence, timely feedback and recognition of their efforts by the instructor worked well, as shown in Della's report.

"Feedback of the teacher like encouragement, praise, and real scores gave me satisfaction. Especially when I was praised in front of the whole class, my self-confidence rocketed!!! Because my work and ability were recognized!!!”

Due to different backgrounds, students' personal experiences and abilities vary. As a result, instructors should diversify assignments and design them as inclusive as possible to fully pique students' interest in learning. Moreover, to give constructive feedback, instructors should continuously track the performance of students, which means instructors need to spend more time and effort.

\subsection{Better Learning Strategies}

$89 \%$ of the respondents reported that Comprehensive English 2 had developed their habit of active learning. The active learning habit entails such learning techniques as previewing, asking questions, frequent self-reflection, and perseverance. Cited below are three students' reflections.

Jerry: "Through skimming, I can get the key points of a text quickly...Learning English is a long task, but now I have the habit of reading English news and magazine..."

Anna: “... good learning needs to know how to ask and answer questions; good learning needs interest and stamina; building confidence is good for finishing study tasks; face up difficulties..."

Jisoo: "These habits are important: asking questions while learning; previewing before class; practicing oral English; learning to reflect."

Students with low motivation and poor self-regulation need a learning community outside the classroom to be reminded or pushed to move forward. Before Comprehensive English 2 was given to Class 2, a Wechat learning group had been created. All group members, including the instructor, should share their pictures of previewed texts. Questions about English learning and suitable English learning materials were warmly welcomed in it. Many students mentioned in questionnaires that this Wechat group was conducive to their learning. Instructors can utilize social networking to establish virtual learning communities to create a healthy climate for active learning in future teaching practice.

In addition to developing some skills specific to foreign language learning and acquiring, students also exercised such critical generic learning skills as communication and metacognition through the course. Effective communication skills are vital to students' future career success. In Comprehensive English 2, the skills were developed through collaborative activities. $88.89 \%$ of the respondents reported that the group tasks and activities in the course had exercised their communication skills. Metacognitive skills play an indispensable role in shaping students into lifelong learners (Doyle, 2008: 135). In the course, the skills were trained mainly through rewriting tasks according to the instructor's feedback. Again, $88.89 \%$ of the respondents agreed that those revision tasks had enhanced their ability to improve performance with feedback. Generic learning skills are fundamental to lifelong learners. In LC teaching, instructors can help students develop such skills with high-order learning activities.

\subsection{Improved Academic Performance}

The grades of the student's coursework and final exams display a noticeable improvement in their academic performance.

Table 1. Grades of Comprehensive English 1's Coursework

\begin{tabular}{llllll}
\hline Score scale & $50-59$ & $60-69$ & $70-79$ & $80-89$ & $90-91$ \\
\hline Number of students & 3 & 8 & 15 & 9 & 1 \\
Out of total & 0.083 & 0.222 & 0.417 & 0.250 & 0.028 \\
\hline
\end{tabular}

Table 2. Grades of Comprehensive English 2's Coursework

\begin{tabular}{llllll}
\hline Score scale & $50-59$ & $60-69$ & $70-79$ & $80-89$ & $90-91$ \\
\hline Number of students & 1 & 2 & 15 & 13 & 5 \\
Out of total & 0.028 & 0.056 & 0.417 & 0.361 & 0.139 \\
\hline
\end{tabular}

As can be seen from tables 1 and 2, in terms of coursework, there is a remarkable decrease of the students' number on scales 50-59 and 60-69, and a significant increase on scales 80-89 and 90-91. 
Table 3. Grades of Comprehensive English l's final exam

\begin{tabular}{llllllll}
\hline Score scale & $20-29$ & $30-39$ & $40-49$ & $50-59$ & $60-69$ & $70-79$ & $80-89$ \\
\hline Number of students & 1 & 3 & 2 & 10 & 7 & 12 & 1 \\
Out of total & 0.03 & 0.08 & 0.06 & 0.28 & 0.19 & 0.33 & 0.03 \\
\hline
\end{tabular}

Table 4. Grades of Comprehensive English 2's final exam

\begin{tabular}{llllll}
\hline Score scale & $40-49$ & $50-59$ & $60-69$ & $70-79$ & $80-89$ \\
\hline Number of students & 2 & 5 & 17 & 10 & 2 \\
Out of total & 0.06 & 0.14 & 0.47 & 0.28 & 0.06
\end{tabular}

Tables 3 and 4 show a disappearance of scales 20-29 and 30-39, and display a sharp increase on scale 60-69 in the final exam. Because the final exam is classroom-based and time-limited, generally, students do not perform as well as they do in coursework. Another evidence of their improved academic performance is that the average score of Comprehensive English 1 is 68.6, while that of Comprehensive English 2 is 72.7. Moreover, the failure rate has decreased from $16.66 \%$ to $2.77 \%$. Interestingly, a slight decrease on scale $70-79$ and a slight increase on scale 80-89 can be seen in tables 3 and 4 . This result can be explained in that qualitative leap takes time and "learning cannot be rushed" (Bransford et al., 2000: 58).

In LC teaching, the instructor listens to his or her students, provides them with targeted help, and shifts learning responsibility back to them. When the instructor values their voices, students participate more actively in learning activities. With targeted help from the instructor, students make expected or sometimes even unbelievable progress. As learning subjects, students are naturally responsible for their learning. However, college students in China are so accustomed to teacher-centered instruction that they often feel perplexed when the instructor stops lecturing. Therefore, the instructor should patiently guide students to shoulder their responsibility gradually. In this study, the number of students who achieved A's in the final exams barely ascended, which could have been improved if more students had undertaken learning responsibility voluntarily. As mentioned above, it takes time to make big steps happen.

\section{Conclusion}

With its focus on learners' development, learning, and learning outcomes, the LC approach has proved effective in unlocking students' potentials, igniting their passion, fostering their lifelong learning skills, and enhancing their English proficiency in this study. Nevertheless, to ensure the effectiveness of the LC approach, instructors must acquire comprehensive knowledge and precise analyses of their students' characteristics. Thanks to the rapid development of technology, this knowledge and analysis can also be attained through virtual communities and social networking, where students may reveal some traits that can never be found in the classroom. Knowing students well can be followed by a harmonious relationship between students and instructors, which can further ease students' learning anxiety to some extent, and thus encourage them to become "more 'open' to the input" (Krashen, 1998: 38).

Growing up as digital natives, college students today demonstrate a deep interest in technology-assisted learning. Therefore, instructors should speed up their process of immigrating into the digital world where their students inhabit and facilitate their learning there as qualified digital immigrants. Moving from traditional instruction to LC one requires both instructors and students to change their roles. However, "the greatest challenge of learner-centered teaching remains bringing the learners along" (Doyle, 2008: xi). While adapting to the new roles in LC teaching, instructors should help their students make discomfort zones into comfort zones in a way a skillful yoga teacher does, which implies a "planned, incremental change" (Weimer, 2002: 188). Finally, like a fine climate is indispensable to a plant's flourishing, a supportive environment is fundamental to the success of LC teaching. When everything is ready, the LC approach will unbind instructors from the podium of sages and release students from the chair of passive receivers, and it will change classes from static, monotonous learning communities into dynamic, lively ones.

\section{Acknowledgments}

This study is sponsored by “Zhejiang Yuexiu University Research Projects” (Grant N2020038).

\section{References}

American Psychological Association. (1997). Learner-Centered Psychological Principles: A Framework for School Reform \& Redesign. Retrieved from https://www.apa.org/ed/governance/bea/learner-centered.pdf 
Anderson, L. W. et al. (Eds.). (2001). A taxonomy for learning teaching and assessing: a revision of Bloom's taxonomy of educational objectives (Abridged Edition). New York: Longman.

Arnett, J. J. (2015). Emerging adulthood: the winding road from the late teens through the twenties (2nd ed.). New York: Oxford University Press. https://doi.org/10.1093/oxfordhb/9780199795574.013.9

Biggs, J., \& Tang, C. (2011). Teaching for Quality Learning at University: What the Student Does (4th ed.). Glasgow: Open University Press, 99, 191.

Bloom, B. S. (1956). Taxonomy of Educational Objectives. Ann Arbor: Longmans.

Bransford, J. D., Brown, A. L., \& Cocking, R. R. (Eds.). (2000). How people learn: brain, mind, experience, and school (Expanded ed.). Washington, DC: The National Academies Press, 58.

Cai, J. G. (2021). A Paradigm Shift of General Education from the Perspective of Curriculum-Based Political and Virtuous Awareness in College English: Interpretation of College English Teaching Guidelines (2020). Technology Enhanced Foreign Language Education, 1, 4.

Daniels, H., Cole, M., \& Wertsch J. V. (Eds.). (2007). The Cambridge Companion to Vygotsky. New York: Cambridge University Press. https://doi.org/10.1017/CCOL0521831040

Dewey, J. (2004). Democracy and Education: An Introduction to the Philosophy of Education. Delhi: Aakar Books, 108.

Doyle, T. (2008). Helping students learn in a learner-centered environment: a guide to facilitating learning in higher education. Sterling: Stylus Publishing, xi, xvii, 135.

Gao, X. H. (2019). Student-centered instructional design models and instructional methods in college in the United States (Doctoral dissertation, Huazhong University of Science and Technology, Wuhan, China). https://doi.org/10.27157/d.cnki.ghzku.2019.004699

Greenall, S., \& Wen, Q. F. (Eds.). (2019). New Standard College English: An Integrated Course (Book 2), Beijing: Foreign Language Teaching and Research Press, 1, 19, 39, 57, 59-61.

Jay, Meg. (2013). Why 30 is not the new 20. Retrieved from https://www.ted.com/talks/meg_jay_why_30_is_not_the_new_20

Krashen, S. (1998). The Natural Approach: Language Acquisition in the Classroom. London/New York/Toronto/Sydney/Tokyo/Singapore: Prentice Hall Europe, 30-32, 32-37, 38-39.

Lave, J., \& Wenger, E. (1991). Situated Learning: Legitimate Peripheral Participation. Cambridge/ New York/ Melbourne/Madrid/Cape Town/Singapore/ Sao Paulo/Delhi: Cambridge University Press. https://doi.org/10.1017/CBO9780511815355

McKeachie, W. J., \& Svinicki, M. D. (2014). McKeachie's teaching tips: strategies, research, and theory for college and university teachers (14th ed.). Belmont: Wadsworth Cengage Learning.

Piaget, J. (1971). Genetic Epistemology. New York: The Norton Library. https://doi.org/10.7312/piag91272

Rogers, C. (1946). Significant aspects of client-centered therapy. American Psychologist, 1, 415-422. https://doi.org/10.1037/h0060866

Rogers, C. (1961). On Becoming a Person. Boston: Houghton Mifflin, 273, 274, $276,277$.

Weimer, M. (2002). Learner-centered teaching: Five key changes to practice. San Francisco: Jossey-Bass, 188.

Xiang, M. Y. (2020). Notes on the curriculum setting of College English Teaching Guidelines. Foreign Language World, 4, 30-31.

Zhao, J. M., \& Gao, X. H. (2019). Align with Learning Outcomes: Construct a Unified Educational Quality Assurance System-Studies of the SC Undergraduate Education Reform in the USA (5). Research in Higher Education of Engineering, 3, 20.

Zhao, J. M., \& Gao, X. H. (2020). Empower Teachers: SoTL and Faculty Development-Studies of the SC Undergraduate Education Reform in the USA. Research in Higher Education of Engineering, 3.

Zhao, J. M. (2016). On the New Three-centered Theory: Concepts \& History. Research in Higher Education of Engineering, 3, 56.

Zhao, J. M. (2017a). Open the Blackbox: The Scientific Foundation of Undergraduate Learning and Development (Part 1)-A Series of Study of the SC Undergraduate Education Reform in the USA (2). Research in Higher Education of Engineering, 3, 52. 
Zhao, J. M. (2018a). Focus on Design: Practices and Methods (part 1)-A Series of Study of the SC Undergraduate Education Reform in the USA (3). Research in Higher Education of Engineering, 2, 44.

Zhao, J. M. (2018b). Focus on Design: Practices and Methods (part 2)-A Series of Study of the SC Undergraduate Education Reform in the USA (3). Research in Higher Education of Engineering, 3, 37.

Zhao, J. M. (2019). Align with Learning Outcomes: Highlights of Course-level Learning Outcome Assessments-Studies of the SC Undergraduate Education Reform in the USA (6). Research in Higher Education of Engineering, 6, 23.

Zhao, J. M. (2019). Support Learning: Learning Environment and Educational Technology-Studies of the SC Undergraduate Education Reform in the USA. Research in Higher Education of Engineering, 2, 25.

Zhao, J. M. (2020). The Unbalanced Balance: A Study of the Issue of "Overemphasizing Research and Devaluing Teaching in Faculty Performance Evaluation-Studies of the SC Undergraduate Education Reform in the USA (8). Research in Higher Education of Engineering, 6, 27.

Zhao, J. M. (2021). Leading the Reform Organizing and Managing the SC Reform-Studies of the SC Undergraduate Education Reform in the USA (9). Research in Higher Education of Engineering, 4, 22.

Zhu, L. (2020). Investigation and Research on the Present Situation of College Students' Online Game Behavior. Journal of West Anhui University, 4, 147.

\section{Copyrights}

Copyright for this article is retained by the author(s), with first publication rights granted to the journal.

This is an open-access article distributed under the terms and conditions of the Creative Commons Attribution license (http://creativecommons.org/licenses/by/4.0/). 